\title{
Vulnerability to Earthquake Hazard: Bucharest Case Study, Romania
}

\author{
Iuliana Armaş $^{1} \cdot$ Dragos Toma-Danila $^{1,2} \cdot \operatorname{Radu}^{\text {Ionescu }}{ }^{1} \cdot$ Alexandru Gavriş $^{3}$
}

Published online: 23 June 2017

(c) The Author(s) 2017. This article is an open access publication

\begin{abstract}
Recent seismic events show that urban areas are increasingly vulnerable to seismic damage, which leads to unprecedented levels of risk. Cities are complex systems and as such their analysis requires a good understanding of the interactions between space and the socioeconomic variables characteristic of the inhabitants of urban space. There is a clear need to develop and test detailed models that describe the behavior of these interactions under seismic impact. This article develops an overall vulnerability index to seismic hazard based on a spatial approach applied to Bucharest, Romania, the most earthquake-prone capital in the European Union. The methodology relies on: (1) spatial post-processed socioeconomic data from the 2011 Romanian census through multicriteria analysis; and (2) analytical methods (the Improved Displacement Coefficient Method and custom-defined vulnerability functions) for estimating damage patterns, incorporated in a GIS environment. We computed vulnerability indices for the 128 census tracts of the city. Model sensitivity assessment tested the robustness of spatially identified patterns of building vulnerability in the face of uncertainty in model inputs. The results show that useful seismic vulnerability indices can be obtained through interdisciplinary
\end{abstract}

Dragos Toma-Danila

toma@infp.ro

1 Department of Geomorphology-Pedology-Geomatics, Faculty of Geography, University of Bucharest, Bucharest, Romania

2 National Institute for Earth Physics, Magurele, Ilfov, Romania

3 Department of Tourism and Geography, Bucharest University of Economic Studies, Bucharest, Romania approaches that enhance less detailed datasets, which leads lead to better targeted mitigation efforts.

Keywords Bucharest $\cdot$ Romania $\cdot$ Seismic loss estimation - Seismic risk - Spatial multicriteria analysis $\cdot$ Vulnerability index

\section{Introduction}

Because over half of the globe's human population lives in cities and the exposure of this urban population to natural hazard-induced disasters is constantly increasing (Gu et al. 2015), the need to understand and define vulnerability in a more comprehensive manner is becoming vital. Urban area expansion, coupled with the increasing complexity of cities, triggers new challenges to explanation of the intricate relationships between new forms of vulnerabilities and the urban context. Recent events prove that societies are becoming increasingly more vulnerable to earthquake damage; it is alarming that since 2004, more than 744,000 people lost their lives due to earthquakes and the tsunamis triggered by them (USGS 2016) during events in Indonesia (2004), Pakistan (2005), China (2008), Haiti (2010), Japan (2011), Nepal (2015), and Italy (2016).

Understanding and being able to measure vulnerability are key factors in managing disaster risk reduction. Only when effectively measured can vulnerability give us a sense of scale for expected consequences and can targets be set in developing resilient building programs (Kasperson and Kasperson 2005; Birkmann 2006). Since seismic hazard cannot generally be diminished, vulnerability is one aspect where efforts can be expended with the goal of disaster risk reduction (Coppola 2007). 
The concept of vulnerability differs across fields and for different spatial levels, mostly due to its multifaceted and scalar-dependent character. Vulnerability is broadly defined as the "potential for loss" (Thywissen 2006). Within this approach, we understand vulnerability as a predictive variable that designates the potential for humans to be harmed relative to an earthquake event's intensity (Ionescu et al. 2009; Duzgun et al. 2011; Walker et al. 2014).

Although many studies have tried to provide solutions for measuring vulnerability, and there is a wide range of vulnerability quantifying methods (for example, Turner et al. 2003; van der Veen et al. 2009; Sterlacchini et al. 2014), a fundamental challenge remains how to make vulnerability operational (Hinkel 2011). The lack of standardized and complex enough data is a major downside and leads to the development of data-driven methods that have little application in circumstances where other types of data are available. This study introduces a new methodology to quantifying seismic vulnerability at an urban scale, which can be easily adjusted to other case study areas with different statistical datasets.

Access to data varies greatly depending on the city selected as a case study; an important question is which aspects should be included in a seismic vulnerability index, and how relevant are these aspects to the specific case study area. Urban systems are highly complex, yet postearthquake inspections point to two major factors (Duzgun et al. 2011; Marquis et al. 2015) that contribute to seismic risk exploration: building characteristics and socioeconomic variables, which impact both mitigation and recovery efforts. For this reason, we refer in this study mainly to these two factors, using socioeconomic indicators and building-damage patterns that are calculated for different seismic hazard scenarios, and applying the latest available data from the census of Romania in 2011 (INS 2017).

\section{Study Area}

The study area is Bucharest, the capital of Romania, a city with approximately two million inhabitants that has and will experience high peak ground accelerations due to earthquakes, which originate from the intermediate-depth Vrancea Source (Fig. 1)—as seismic hazard studies like Giardini et al. (2013) and Pavel et al. (2016) show. This seismic source is located $<150 \mathrm{~km}$ northeast of Bucharest.

The 4 March 1977 earthquake was responsible for 1424 casualties and the collapse of more than 33 medium and large buildings in Bucharest; the 10 November 1940 earthquake led, through the collapse of the Carlton building, to 140 deaths. In Fig. 2, a map of the medium and high-rise buildings that were completely or partially damaged during the 1940 and 1977 earthquakes, together with the locations of buildings individually evaluated by construction specialists and classified as being in the most endangered seismic risk class I (Bucharest General Municipality 2016), is presented, with the purpose of providing a glimpse of the scale of seismic damage in Bucharest.

Because some time has passed since the last major earthquake with high damage potential, and new political, economic, and development phases have occurred, it becomes necessary to assess the contemporary seismic vulnerability of Bucharest. The common perception, at the level of the general populace, is that the city would be greatly affected by an earthquake (Armaş 2008). Recent studies that refer to the seismic vulnerability and risk of Bucharest at a city level, such as Armaş (2012), Lang et al. (2012), Toma-Danila et al. (2015a), and Pavel and Vacareanu (2016), all show critical issues that need to be further analyzed.

The city is divided in six sectors (city districts). These are administrative regions each with its own city hall, mayor, and assembly. Sectors radiate from the city center and as such each has within it a slice of the center, middle, and outskirts of the city. The boundaries do not take neighborhoods into account and will sometimes simply cut through the middle of a neighborhood. Sectors typically have a population of about 300,000 and are relatively independent of each other in the sense that one can decide to set up a fund to rehabilitate at-risk buildings while another can choose not to do so. With the sectors having their own city halls and assemblies it is not uncommon for the residents of one building to be governed by a mayor from the ruling party while their neighbors from across the street are governed by another mayor from the opposition.

\section{Methods and Data}

The availability of data for Bucharest shaped the selection of methods for the quantification of vulnerability, and the development of new procedures. The overall methodology can be considered hybrid-integrating empirical assumptions and relations, analytical methods for the evaluation of building behavior or statistical analysis, with the goal of explaining the potential distribution of vulnerability due to a credible earthquake.

\subsection{Overall Methodology}

Our research belongs to the broad field of semi-quantitative vulnerability assessment and index construction. It integrates GIS-based modeling along with a spatial multicriteria analysis of social vulnerability (Ouma et al. 2011). To 


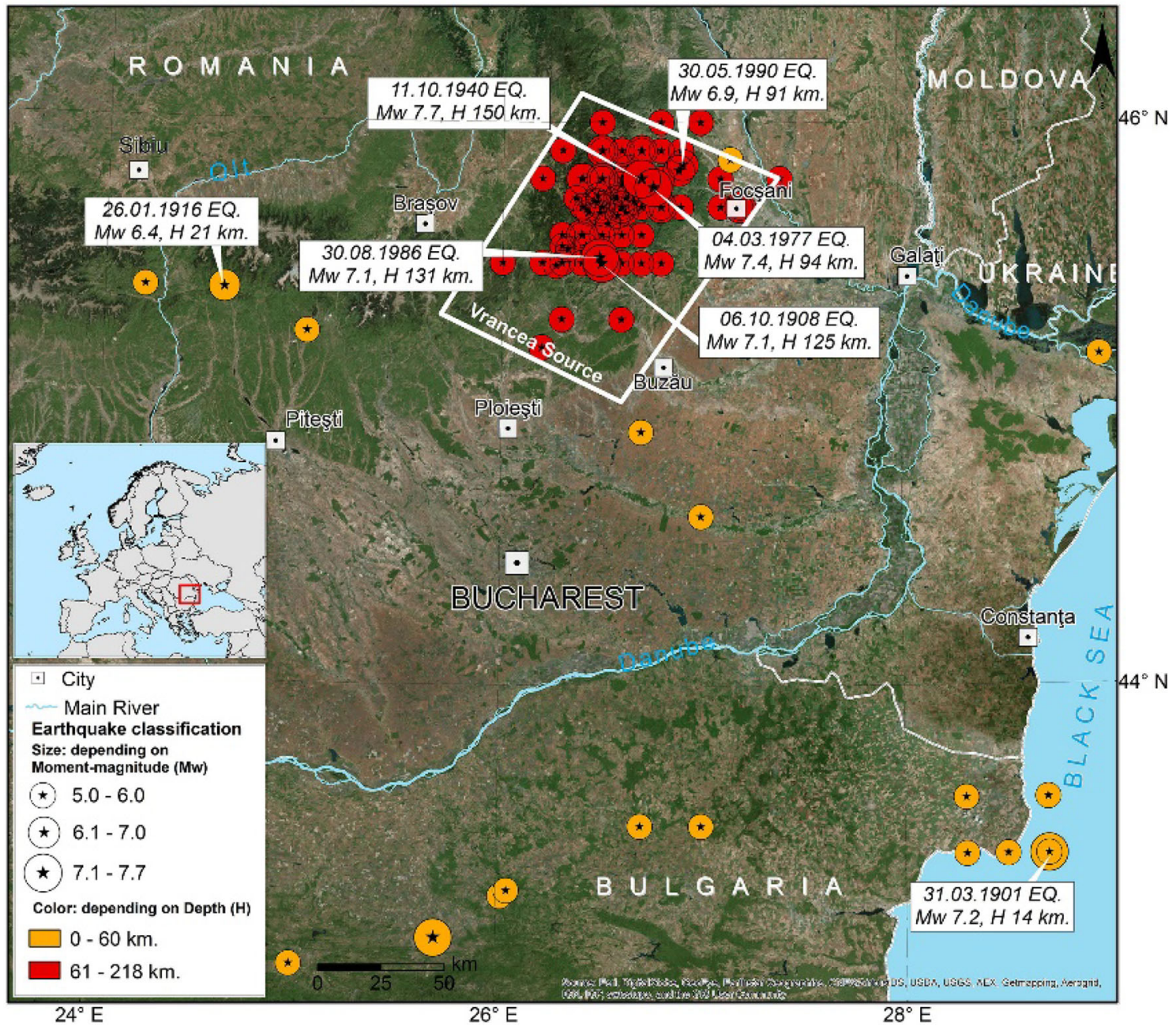

Fig. 1 Earthquakes near Bucharest with moment-magnitude $\geq 5$ between 1900 and 2016. Data source NIEP (2016)

this our approach adds a building loss estimation component obtained by using analytical methods. The GIS-based multicriteria technique combines the information from several indicators (criteria) to form a single index of social vulnerability (Chen et al. 2010). Figure 3 shows the flowchart guiding the analytical process.

The social vulnerability index construction involved literature review and expert judgement followed by the selection of a core set of social vulnerability dimensions and indicators (Blaikie et al. 1994; Fekete 2009). The census data variables included in the construction of social vulnerability indicators are presented in Table 1, and were selected due to availability and their capability to reflect social vulnerabilities over multiple dimensions, such as social structure, education, housing, and social dependence. This capability was demonstrated also in a preliminary study (Armaş and Gavriş 2013), where the same variables were selected, but the overall level of detail of the analysis was lower.
The analytical steps in the construction of the social vulnerability index relied on principal component analysis (PCA). The four social vulnerability dimensions-social, education, housing, and social dependence, as identified in Table 2-explained over $88 \%$ of the variance within a middling value for Kaiser-Meyer-Olkin (KMO) Measure of Sampling Adequacy. The advantage of KMO is found in the fact that it suggests the presence of latent factors, meaning that the statistical exploration of the data may be conducted easily; it is also a double check diagnostic alongside Bartlett's test. A more detailed description of this procedure can be found in Armaş and Gavriş (2016).

The four dimensions for which we were able to associate statistical results were further integrated into a criteria tree using the SMCE (Spatial Multi-Criteria Evaluation) module of the Ilwis software (ITC 2001), and weighted according to expert judgment and scenario testing. In the criteria tree, there were also spatial constrains (barren land 


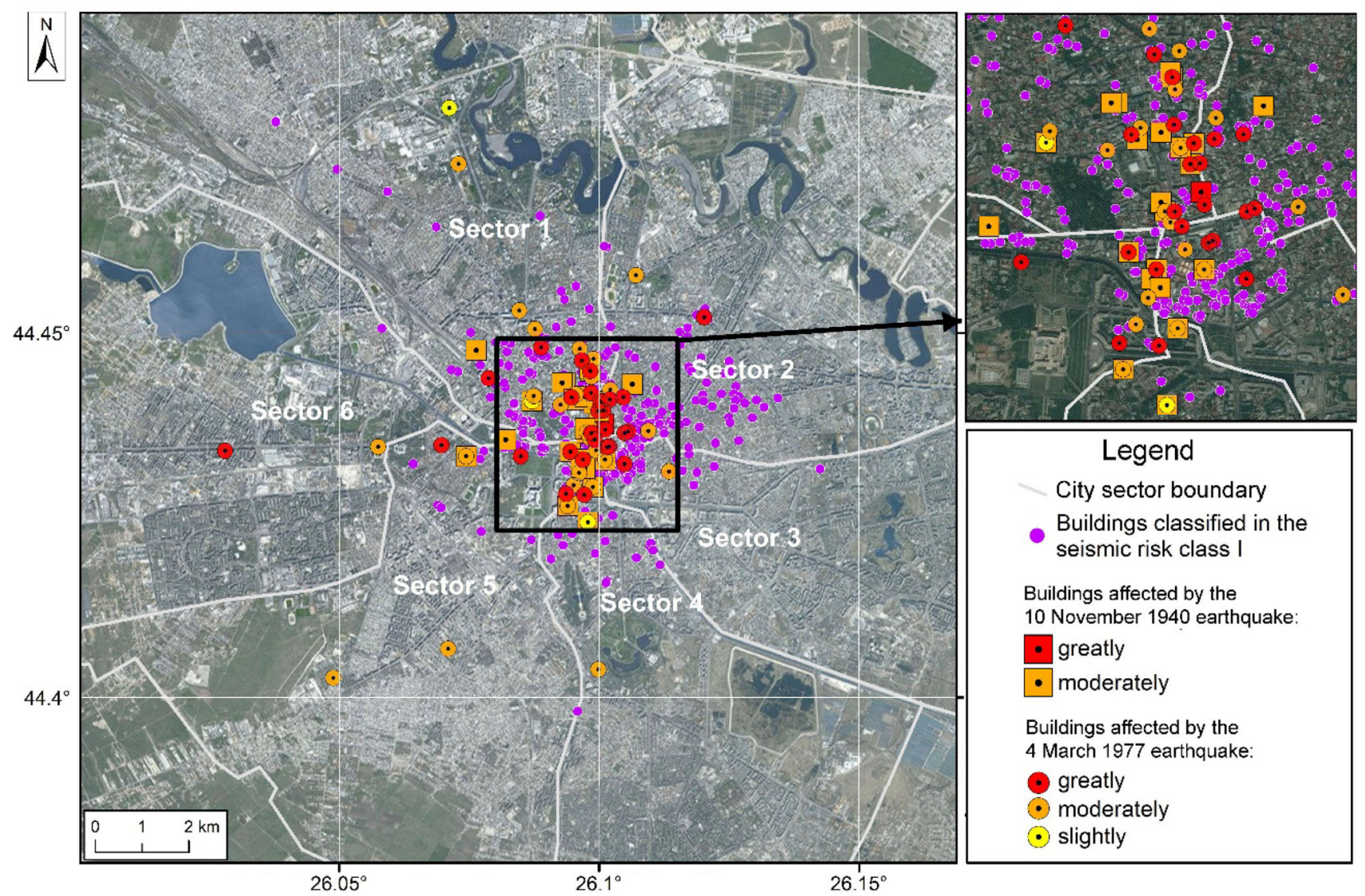

Fig. 2 Map of the buildings affected by the 1940 and 1977 earthquakes in Bucharest, and the buildings classified in seismic risk class I, according to Bucharest General Municipality (2016)

Fig. 3 Methodological

flowchart of research design. Darker boxes show the main methods and procedures applied to datasets

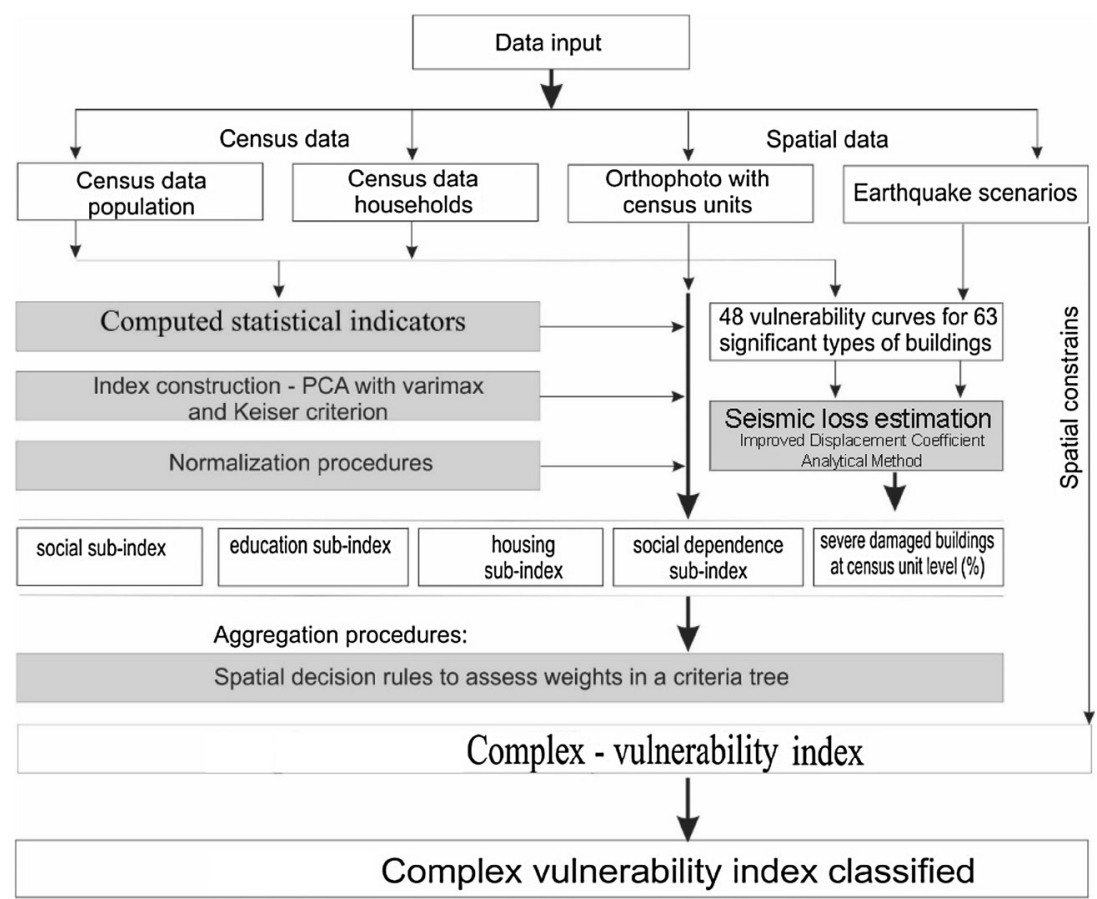


Table 1 Census data variables selected for inclusion in vulnerability index. Source Armaş and Gavriş (2013)

\begin{tabular}{|c|c|c|c|}
\hline Total no. of persons on census tract (census population) & $N p^{t}$ & Total no. of unemployed persons on census tract & $N u^{t}$ \\
\hline Total no. of households on census tract & $N h^{t}$ & Total no. of men on census tract & $N m^{t}$ \\
\hline Total no. of children on census tract & $N c^{t}$ & $\begin{array}{l}\text { Total area of household rooms (bedrooms, living rooms) on } \\
\text { census tract }\end{array}$ & $N a^{t}$ \\
\hline Total no. of women on census tract & $N w^{t}$ & Total no. of rooms on census tract & $N r^{t}$ \\
\hline $\begin{array}{l}\text { Total no. of women having } 3 \text { or more children on census } \\
\text { tract }\end{array}$ & $N w 3^{t}$ & Total no. of private/owned houses on census tract & $N o^{t}$ \\
\hline Total no. of women of over $15 \mathrm{y}$ giving birth to a live child & $N w 15$ & $\begin{array}{l}\text { Total no. of private/owned houses with } 5 \text { or more rooms on } \\
\text { census tract }\end{array}$ & No5 $5^{t}$ \\
\hline $\begin{array}{l}\text { Total no. of persons with minimum education level on } \\
\text { census tract }\end{array}$ & $N m e^{t}$ & Total no. of economically active population & $N c v t^{t}$ \\
\hline Total population over 10 years of age & $N p 10^{t}$ & Total no. of social dependent people & $N d^{t}$ \\
\hline Total area of occupied space in the residences & $N h o^{t}$ & Total population over 65 years of age & $N e^{t}$ \\
\hline
\end{tabular}

Table 2 Social vulnerability dimensions and loadings of variables on the components. Source Armaş and Gavriş (2016)

\begin{tabular}{|c|c|c|c|c|c|}
\hline \multirow[t]{2}{*}{ Dimension and variance explained } & \multirow[t]{2}{*}{ Indicator } & \multicolumn{4}{|c|}{ Component } \\
\hline & & 1 & 2 & 3 & 4 \\
\hline Social & Dwelling population density & 0.855 & 0.418 & & \\
\hline 27.867 & Widows female population in total population & -0.800 & & & 0.533 \\
\hline \multirow[t]{3}{*}{+} & Elderly (over 65 years) & -0.796 & & & 0.526 \\
\hline & Female population in total population & -0.774 & -0.453 & & \\
\hline & Room occupancy per household & 0.746 & & -0.583 & \\
\hline Education & Minimum level of education & & 0.946 & & \\
\hline 24.177 & Unemployed population (inactive population) & & 0.830 & & \\
\hline+ & $\begin{array}{l}\text { Women with more than } 3 \text { children (in total women who gave } \\
\text { birth) }\end{array}$ & 0.437 & 0.829 & & \\
\hline Housing & Housing density & 0.394 & & -0.895 & \\
\hline 21.880 & Average room area per person on census tract & -0.390 & & 0.879 & \\
\hline \multirow[t]{2}{*}{-} & Average household room area on census tract & & & 0.814 & \\
\hline & Average no. of private/owned houses with 5 or more rooms & & 0.585 & 0.628 & \\
\hline Social dependence & Dependent people in total population & & & & 0.929 \\
\hline 14.476 & Children in total population & 0.319 & 0.518 & & -0.636 \\
\hline \multicolumn{6}{|l|}{+} \\
\hline $\begin{array}{l}\text { Kaiser-Meyer-Olkin measure of } \\
\text { sampling adequacy } 0.749\end{array}$ & $\begin{array}{l}\text { Extraction method: principal component analysis. Rotation } \\
\text { method: Varimax with Kaiser normalization }\end{array}$ & & & & \\
\hline & Rotation converged in 6 iterations & & & & \\
\hline
\end{tabular}

and parks) as Boolean inputs (true/false), but these constrains were not considered during weighting.

Input values were normalized from 0 to 1 , by dividing them based on the maximum value in the range (that is the maximum value-function approach). For the normalization of the average dwelling room area per census tract we used a combination of cost-benefit assumptions relative to social vulnerability increase (with a U-shape up to $23 \mathrm{~m}^{2}$ and a descending curve to the maximum value of over $34 \mathrm{~m}^{2}$ room space), according to the values offered by Eurostat (2014). In 2012, Romania had the highest rates of overcrowding in Europe at $51.6 \%$, and an average floor area of $46.9 \mathrm{~m}^{2}$ per dwelling. It should be noted that the average dwelling size in Europe was significantly larger, at $102.3 \mathrm{~m}^{2}$ (Eurostat 2014). All indicators were understood as increasing conditions for social vulnerability, except for the "Average no. of private/ owned houses with five or more rooms" variable in Table 2. The presence of large private houses in an area was considered an indication of decreased social vulnerability. It was also normalized using the maximum value-function approach. All other indicators were understood as increasing conditions for social vulnerability.

Weights were assigned to the indicators describing a dimension, as well as to the four groups of dimensions 
introduced in the criteria tree to indicate their relative importance with respect to social vulnerability. In assigning weights, we applied the pairwise comparative method, developed by Saaty (1980) in the Analytic Hierarchy Process (AHP) and implemented in the SMCE-Ilwis module. The AHP method is based on expert opinion and reduces the complexity of the conversion of subjective assessments of relative importance to a sequence of pairwise comparisons. Each comparison is a two-part question: "How important is indicator $I_{i}$ relative to indicator $I_{j}$ ?" The set of overall weights was based on rank orders provided by national and international experts (one or two experts representing the fields of seismology, geology, geomorphology, civil protection, civil constructions, psychology, and sociology) who proved through their results by questionnaire forms on the importance of each criterion for the social vulnerability model (for example, Armaş 2006, 2008; Armaş and Avram 2008).

In SMCE-Ilwis module, the responses use the following nine-point scale expressing the intensity of the preference for one indicator versus another, and also calculates a consistency of judgements between pairs: $1=$ Equal importance or preference; $3=$ Moderate importance or preference of one over another; $5=$ Strong or essential importance or preference; $7=$ Very strong importance or preference; $9=$ Extreme importance or preference. Based on Saaty (1980), if the consistency of the conducted comparisons is lower than 0.10 , the pairwise comparison matrix has an acceptable consistency and the weight values are deemed valid.
Table 3 summarizes the normalized weights for the indicators saturating the four dimensions of the complex social vulnerability index. The overall earthquake vulnerability index for Bucharest was computed as an aggregate of weighted linear combination. As can be seen in Table 3 and Fig. 3, the vulnerability patterns of residential buildings are added as an additional fifth dimension; they are the result of a different computation procedure, described in the following subsection.

The result of the weighting process was reclassified into four vulnerability classes, based on the distance from the average of the value obtained by each census tract. Average vulnerability of census tracts after weighting was 0.51 with a median value of 0.59 and a standard deviation of 0.15 . The low vulnerability class result included vulnerability values smaller than 0.4 , the upper bound of the medium vulnerability class was 0.6 ; for the high vulnerability class the upper bound was 0.7 , and the very high vulnerability class included values over 0.7 .

Since spatial multicriteria analysis involves many indicators, it is increasingly recognized that the outcomes of this approach are prone to inherent uncertainties related to the errors and variability in model choice, availability, heterogeneity, errors in the input data, and/or errors in the weighting process based on human judgment (Crosetto et al. 2000; Crosetto and Tarantola 2001; Chen et al. 2011; Feizizadeh et al. 2014). Therefore, we decided to test the influence of assumptions made in the weighting process (Table 3) and input data values (Table 1) on the specific outcomes and included uncertainty and sensitivity analyses

Table 3 Normalized weights of social, educational, housing, and social dependence indicators

\begin{tabular}{lll}
\hline Dimensions and weights & Indicator & Weights \\
\hline Social & Dwelling population density & 0.348 \\
0.264 & Widows female population in total population & 0.133 \\
& Elderly (over 65 years) & 0.133 \\
& Female population in total population & 0.064 \\
& Room occupancy per household & 0.323 \\
Education & Minimum level of education \\
0.153 & Unemployed population (inactive population) & 0.143 \\
& Women with more than 3 children (in total women who gave birth) \\
Housing & Housing density & 0.429 \\
0.063 & Average room area per person on census tract & 0.429 \\
& Average household room area on census tract & 0.300 \\
Social dependence & Average no. of private/owned houses with 5 or more rooms \\
0.189 & Dependent people in total population \\
Residential building vulnerability patterns, & Children in total population \\
considering seismic hazard variability & & 0.300 \\
0.330 & & 0.300 \\
\hline
\end{tabular}


of the building-vulnerability model results, as further analysed in Sect. 4.

Uncertainty analysis aimed to identify if rank reversals occur with changes in weights and input data values (Crosetto and Tarantola 2001). Sensitivity analysis explored the model response to changes in input values by testing the relationships between the inputs and the output of the applied model (Saltelli et al. 2000; Crosetto and Tarantola 2001; Chen et al. 2010; Ravalico et al. 2010). The robustness of the results were analyzed using the methods for sensitivity analysis from DEFINITE toolbox, based on frequency tables from 10,000 simulations run after introducing uncertainty ranges in input values and assigned weights (Janssen and van Herwijnen 1994).

Although the methodology seems to focus on simplified aspects of a complex system (the urban environment), its flexibility allows the integration of multiple types of input data (whether statistical indices or variables obtained through other methods) and facilitates the testing of multiple hypotheses in an effort to explain links between different socioeconomic and habitat dimensions.

\subsection{Vulnerability Assessment for Residential Buildings}

As represented in Table 3, residential building vulnerability, seen as dependent on hazard variability, was introduced as a separate condition in the criteria tree, normalized, and weighted in the final total vulnerability complex index. Through this choice, we emphasized the importance of building vulnerability in the analysis, especially in the urban context, since buildings are the elements that cause most of the seismic losses. This line of thought is aptly captured by the common phrase: earthquakes don't kill people, buildings do.

That is why we tried to determine which areas of the city have the greatest residential building vulnerability. The assessment of individual buildings can yield the best results, but the process is both time and cost consuming. In Bucharest, only 855 buildings (located mostly in the city center) were evaluated and classified according to their vulnerability by the Bucharest General Municipality (2016), although the total number of residential buildings in Bucharest is 131,875. Approximately 40,000 of these structures are older than 1963; they date from a construction period when no seismic design regulations were available. In other words, reliable information about building vulnerability can only be found for $<0.65 \%$ of the city's buildings. Thus, to have a wider perspective, we used a more generalized approach as is found in other contemporary studies, like Erdik et al. (2011) or Karmizadeh et al. (2017). This approach relies on analytical methods, especially the Improved Displacement Coefficient Method
(IDCM), as well as statistical data such as the number of buildings per construction period, building material, and structure height. These data provide valuable insight into building damage patterns at the city level.

IDCM is an analytical method developed along with the HAZUS initiative (FEMA 2014). The method involves the modification of the displacement demand of an equivalent single-degree of freedom system (this simplifies building characteristics) by multiplying it with a series of coefficients to generate an estimate of the maximum displacement demand of the nonlinear oscillator (Molina et al. 2010). We chose this method due to the good performance it showed for the study area (Toma-Danila et al. 2015a) and its successful implementation within the widely used SELENA (Seismic Loss Estimation using a logic tree Approach) open-source software for seismic loss estimation (Strasser et al. 2008).

Census data-collected by Romania's National Institute of Statistics in 2011-for residential buildings in 128 distinct census tracts within the city were used for computing building loss estimations. Recently, a set of 48 vulnerability (more specifically capacity and fragility) functions, custom developed as well as adapted from the literature, were associated with major building typologies in Romania and enabled implementation of a near real-time system for estimating Seismic Damage in Romania-SeisDaRo (Toma-Danila et al. 2015b). The SeisDaRo building typologies account for nine types of construction materials (such as adobe, reinforced or unreinforced masonry, wood, and reinforced concrete), three building height classes, and four construction periods representative for Romania (PreCode-before 1963, LowCode-1963-1977, MediumCode-1978-1991, and HighCode-after 1991). In order to adopt this classification, considered relevant to Bucharest (Toma-Danila et al. 2015a), a specific conversion methodology was applied to the 2011 original dataset (Fig. 4; Table 4). The methodology comprises reclassification and statistical derivation, both based on customdefined profiles and GIS interpretation. Detailed methodological steps can be found in Toma-Danila and Armaş (2017). The arrangement allows for the integration of the 2011 Bucharest data within SeisDaRo, and has proved to be a useful step in the quick estimation of possible earthquake effects in our study.

Since vulnerability functions cannot offer a complete answer to the question of which areas are more endangered, we run simulations with three distinct seismic scenarios. These simulations exposed building damage patterns at minimum, median, and maximum credible damaging levels. As seen in Fig. 1, the Vrancea intermediate-depth seismic source, located at the contact between the East European Plate and the Intra-Alpine and Moesian Subplates, is the only source responsible for damaging 




Fig. 4 Distribution of the total number of buildings in Bucharest (left) and the number of buildings erected before 1945, therefore without seismic design code consideration (right). Source Romanian 2011 census (INS 2017)

Table 4 Original structure of the 2011 census dataset for residential buildings

131,875 buildings in total

128 census tracts (CT) for Bucharest (variable size)

For each CT, number of residential buildings according to:

Construction period: <1919, 1919-1945, 1946-1960, 1961-1989, 1990-2002, 2003-2011 (years)

$\searrow$ For each construction period: building height: $<2 \mathrm{~S}, 2-4 \mathrm{~S}, 5-7 \mathrm{~S}, 8-10 \mathrm{~S},>10 \mathrm{~S}$ (S = Storeys)

Construction material: reinforced concrete, precast concrete, masonry with concrete floor, masonry with wooden floor, wood, adobe, other materials, mixed materials

acceleration values in Bucharest. Hazard studies such as those by Giardini et al. (2013) and Pavel et al. (2016) reflect this aspect. Therefore, all selected scenarios are for this source. Two of these scenarios are based on realrecorded values (for the 1990 and 1977 Vrancea earthquakes with moment-magnitudes of 6.9 and 7.4, respectively) and one (for the maximum possible Vrancea earthquake, with moment-magnitude of 7.8) is based on a recent approach relying on nonlinear seismic response evaluation to a synthetic signal from a point source with a mechanism similar to the one of the 1940 earthquake (Marmureanu et al. 2010). These scenarios are deterministic and were selected due to their capability to highlight potential differences inflicted by local site effects and due to their different magnitude ranges, which cover the spectrum between maximum and inceptive damage levels (Toma-Danila and Armaş 2017). All ground motion parameters used are at surface level, and consider site conditions, propagation effects, and frequency ranges, a very important aspect for intermediate-depth Vrancea earthquakes. Probabilistic scenarios for Bucharest do not yet provide sufficient insights into the very local variance of ground motion parameters, which, as demonstrated by previous events, vary considerably both within and between events, and were thus considered unsuitable for reflecting vulnerability patterns, but proved more useful in testing seismic risk dynamics.

The individual scenario results consisted of estimated numbers of damaged buildings per census tract, with probabilities for different damage states (none, slight, medium, extensive, and complete damage). The ratio between estimated buildings with complete damage and their total number was used, which allowed normalization between census tracts of different sizes. The ratios of the three earthquake scenarios were averaged and normalized on a scale from 0 to 1 and were introduced as a separate 
spatial factor in the total vulnerability criteria tree. This procedure is one of the steps that make the proposed methodology innovative and presumably more insightful.

\section{Results}

To highlight the most vulnerable built areas of Bucharest, we averaged the three seismic scenarios into a built environment index, based on severely damageable buildings in case of an earthquake. This approach is justified given that residential building loss estimates are one of the key dimensions in overall earthquake vulnerability computations. Subsequently, an overall vulnerability map was produced.

\subsection{Residential Buildings}

The residential building loss estimates (Fig. 5) showed that medium to high values are to be expected within the Bucharest city center and its neighborhoods, which include many old houses and small apartment buildings. The medium and high-rise blocks of flats built during the communist era (for example, in the Militari, Berceni, Titan, Pantelimon, and Colentina neighborhoods in Fig. 6), are not expected to be especially vulnerable to Vrancea earthquakes, although in case of even one collapse from such a building, the risk implications can be significant, considering their traditional high number of residents. This was exposed by the 4 March 1977 earthquake, and was described in detail by Balan et al. (2016). High building vulnerability can be seen in some of the peripheral areas of the city, and, within Sectors 5 and 2, is mainly explained by the poor construction quality of small buildings, which are also more numerous in these sectors than in other areas. This pattern finds its explanation in the city's historical evolution-in the 1950s, surrounding rural areas were incorporated (as in other sectors but here more so), yet urban development work focused solely on the main arteries. As such there are large, undeveloped, rural looking, areas that are part of the city, particularly in the periphery and where the population was and is economically underdeveloped. Owing to comparatively low land prices these areas have begun to attract various real estate developments, which, in time, will likely change the vulnerability pattern of the built environment of Bucharest.

\subsection{Overall Vulnerability Map}

The result of the applied multicriteria analysis is exhibited in the complex overall vulnerability map (Fig. 6), which shows dense, concentrated areas of very high vulnerability
Fig. 5 Map showing the results of the vulnerability assessment for residential buildings; values are normalized between 0 and 1

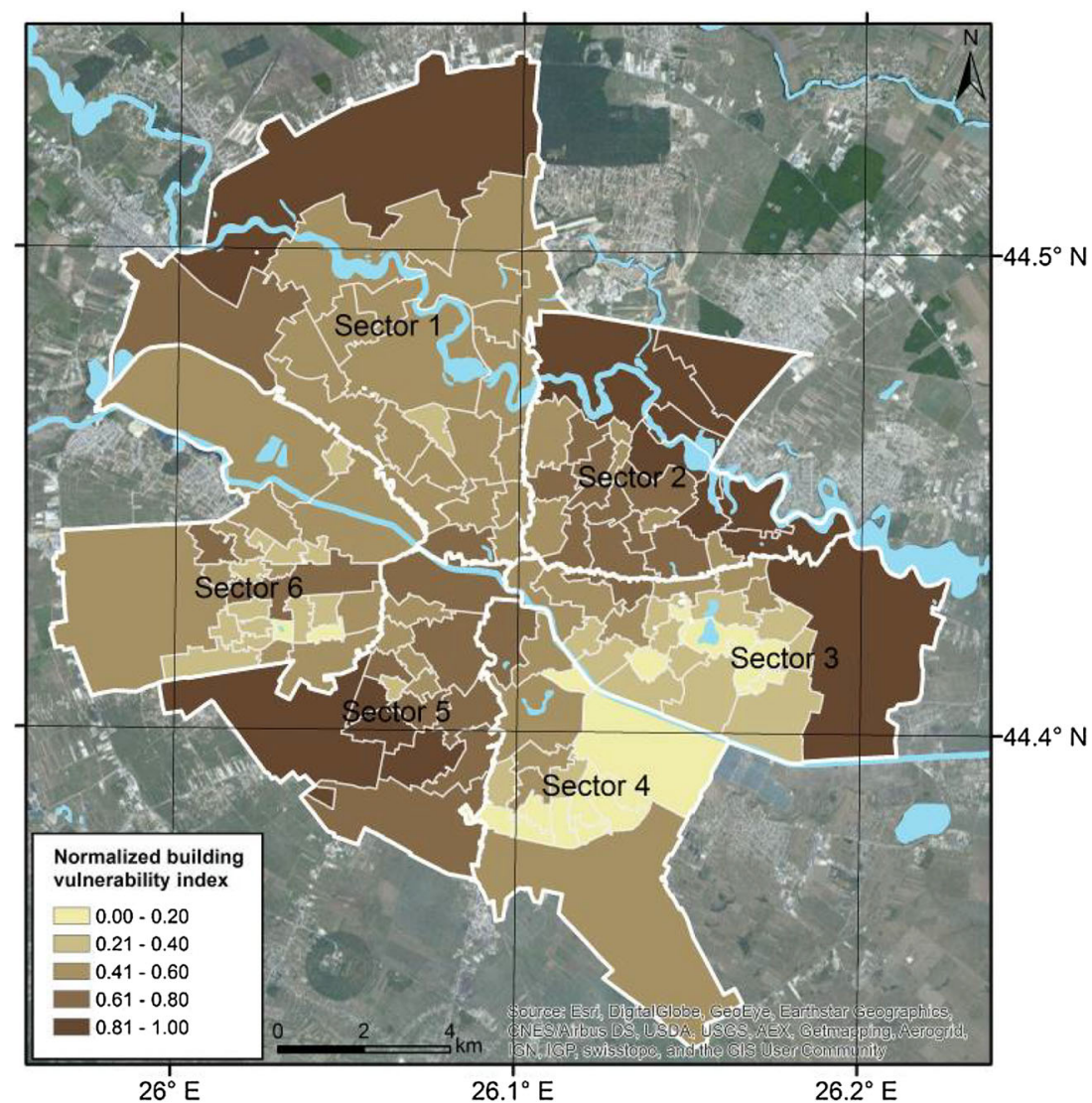


Fig. 6 Overall vulnerability map of Bucharest. The analysis was performed at census tract level. The graph shows the percentage of census tracts in each vulnerability class

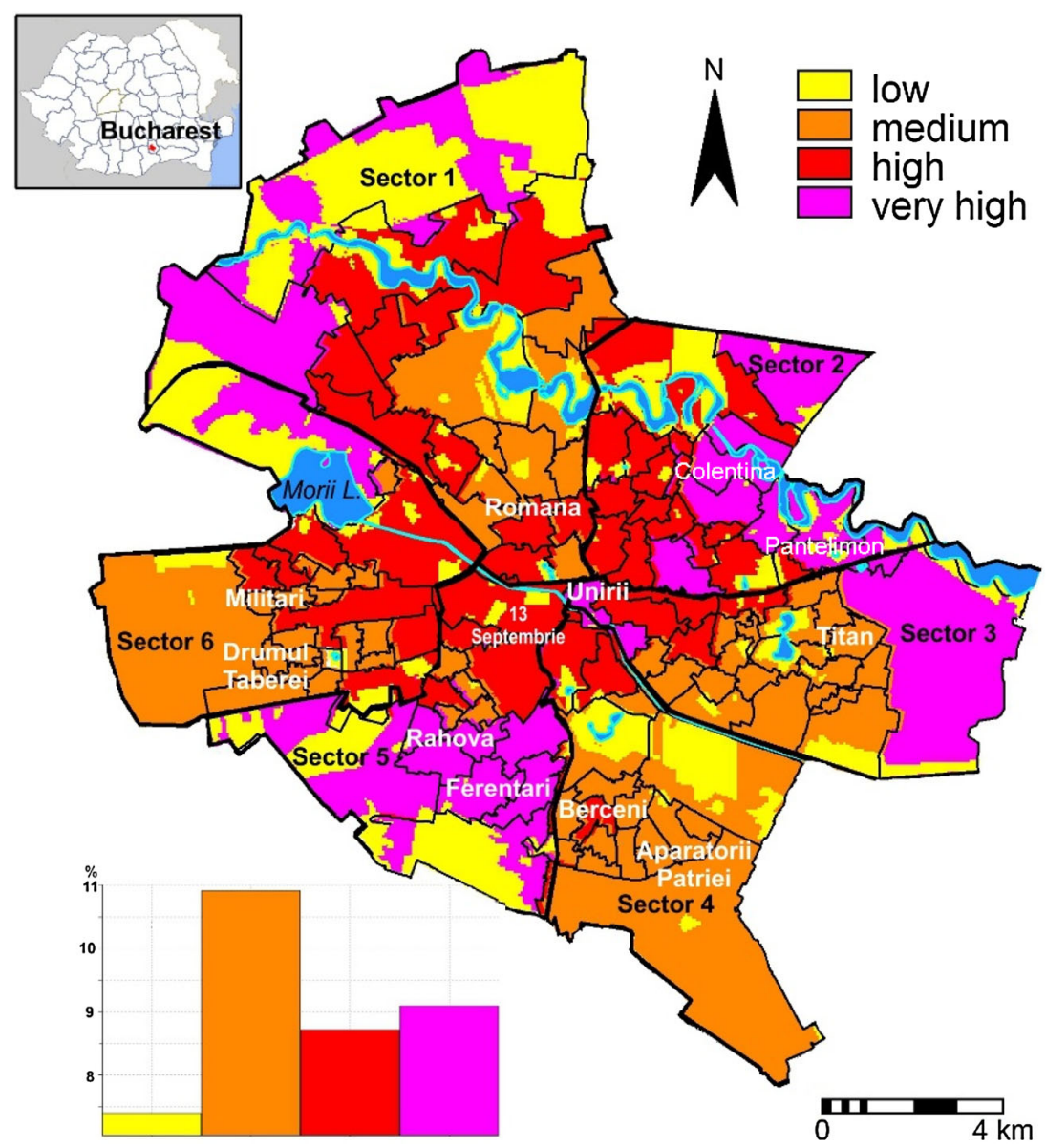

in most of the peripheral zones of the city where more small residences tend to be found rather than large blocks of flats. The areas identified as being vulnerable reveal an image validated by past events and the results of previous studies (Rufat 2009; Trendafiloski et al. 2009; Armaş 2012; Armaş and Radulian 2014; Toma-Danila et al. 2015a).

High vulnerability values can be found in almost the entirety of Sector 5 and in significant areas of Sectors 1, 2, 3 and 6, areas where considerable groups of vulnerable people live in buildings constructed with weak materials and without respect to adequate seismic standards. In these areas, where small buildings are concentrated, the number of direct casualties should not be considerable, since, if casualty levels observed during past events characterize future seismic events, the collapse of small buildings in Bucharest should not produce as many victims as the collapse of medium or high-rise buildings. Sector 4 has the lowest overall vulnerability; this is due to a combination of low building vulnerability and the district's low social vulnerability profile. Within some sectors, a clear discrepancy exists between high and low vulnerability areas. This proves that many Bucharest's sectors are administrative divisions not well represented by structural uniformity. The city center is fragmented across six administrative regions (the sectors) and while its vulnerabilities are shared the administrative responses are unique. This leads to a situation where one might observe six completely different approaches to mitigation in an area less than two square miles. While this provides a natural experiment that might be of scientific interest it also fragments mitigation efforts and hinders adaptation flowing from structural similarities. It is essential to develop the city as an open mechanism rather than a space that is designed to hide massive gaps in wealth, education, and safety.

A distinct cluster of high vulnerability emerges in the Rahova-Ferentari area of Sector 5 (Fig. 6). The reasons for this vulnerability cluster are the age and precarious quality of the housing, accompanied by social issues: massive deindustrialization, high unemployment, and other associated factors. A similar pattern can be seen in Sector 2 .

An important aspect impacting the seismic risk is the relatively high vulnerability of the central zone-the Romana and Unirii Square areas. Significant real losses were produced here by the 4 March 1977 earthquake (Fig. 2), and significant losses can still occur in the future. In the central area, there are many old and vulnerable buildings that can collapse under the impact of any Vrancea earthquake similar to the 1940 and 1977 major seismic 
Table 5 Characteristics of the four census tracts selected for uncertainty analysis, in terms of number of buildings and loss estimation results for the maximum earthquake scenario, according to different construction materials (defined according to SeisDaRo classification)

\begin{tabular}{|c|c|c|c|c|c|c|c|c|c|}
\hline \multirow{2}{*}{$\begin{array}{l}\text { Census } \\
\text { tract ID }\end{array}$} & \multirow{2}{*}{$\begin{array}{l}\text { Type of } \\
\text { indicator }\end{array}$} & \multicolumn{8}{|c|}{ Construction material } \\
\hline & & Adobe & $\begin{array}{l}\text { Unreinforced } \\
\text { masonry } \\
\text { bearing walls } \\
\text { with flexible } \\
\text { floors }\end{array}$ & $\begin{array}{l}\text { Unreinforced } \\
\text { masonry } \\
\text { bearing walls } \\
\text { with rigid } \\
\text { floors }\end{array}$ & $\begin{array}{l}\text { Reinforced or confined } \\
\text { masonry bearing walls } \\
\text { or retrofitted (overall } \\
\text { strengthened) masonry } \\
\text { buildings }\end{array}$ & $\begin{array}{l}\text { Wood } \\
\text { structures }\end{array}$ & $\begin{array}{l}\text { Concrete } \\
\text { shear } \\
\text { walls }\end{array}$ & $\begin{array}{l}\text { Concrete } \\
\text { frame with } \\
\text { unreinforced } \\
\text { masonry } \\
\text { infill walls }\end{array}$ & $\begin{array}{l}\text { Precast } \\
\text { concrete } \\
\text { walls }\end{array}$ \\
\hline 401 & \multirow{4}{*}{$\begin{array}{l}\text { Total number } \\
\text { of } \\
\text { buildings }\end{array}$} & 34 & 657 & 546 & 79 & 37 & 64 & 252 & 10 \\
\hline 507 & & 3007 & 183 & 541 & 123 & 99 & 629 & 1541 & 87 \\
\hline 202 & & 2339 & 329 & 868 & 227 & 245 & 116 & 1476 & 216 \\
\hline 207 & & 541 & 253 & 359 & 94 & 15 & 137 & 635 & 71 \\
\hline 401 & \multirow{4}{*}{$\begin{array}{l}\% \text { of } \\
\text { buildings } \\
\text { affected by } \\
\text { the } \\
\text { maximum } \\
\text { possible } \\
\text { earthquake }\end{array}$} & 14.7 & 16.0 & 10.3 & 8.9 & 2.7 & 7.8 & 8.7 & 0.0 \\
\hline 507 & & 16.2 & 16.4 & 10.0 & 5.7 & 3.0 & 8.1 & 26.5 & 8.0 \\
\hline 202 & & 17.9 & 17.9 & 11.3 & 7.0 & 3.7 & 11.2 & 29.5 & 8.8 \\
\hline 207 & & 18.3 & 18.2 & 11.7 & 9.6 & 6.7 & 12.4 & 23.5 & 7.0 \\
\hline
\end{tabular}

events. The latest report from the Bucharest General Municipality (2016) shows that 350 buildings in this area belong to the seismic risk class I (the most vulnerable) and 326 are classified in the seismic risk class II out of 855 buildings built before 1977. Many such buildings belong to the PreCode period, and were built before 1963 when seismic design was not compulsory. A compounding issue is that many of these buildings are inhabited by people unwilling or unable to consolidate them (apartments are primarily owned by retirees, contain small business offices, or are occupied by people with low incomes). This retrofitting process (Necula et al. 2002) is also hampered by legal ownership hurdles to overcome as numerous properties were confiscated by the communist regime and the process of returning these properties to their previous owners is, a quarter of a century after the fall of communism, not yet complete. Furthermore, buildings in the area have ground floor commercial spaces allocated to restaurants and entertainment venues, which attract pedestrian traffic and increase the number of potential casualties in an earthquake.

\subsection{Uncertainty and Sensitivity Analysis}

Given the significant weight assigned to building collapse in our overall index, we next ran the uncertainty and sensitivity tests on building vulnerability results in case of a maximum possible Vrancea earthquake. This approach was also motivated by the fact that data relaying on experimental and deterministic analysis are more prone to errors, an important issue in the context of the vulnerability of the physical environment to earthquakes in Bucharest. Moreover, the census data included some innate errors during the 2011 census record process (Armaş and Gavriş 2016). We tested the effects of uncertainty in the input values relative to the built environment and the assigned weights on the stability of ranking results. As input criteria, we used the construction period, the edifice height, and the construction material of buildings. We chose to run this analysis for the four top-ranking census tracts to better highlight the results and spatial relationships (Tables 5, 6). The change scenarios tested in this research were between 10 and $30 \%$ increase or decrease in weights and in the criteria values describing the built environment. Results (Fig. 7) revealed that the top part of the ranking is very stable; the tract with ID 401 (the first tract-01-in the fourth sector-4) ranked first, and maintained this position regardless of weight assignment or input data uncertainties. But this same tract (401) displayed also the highest fluctuations in the ranking when uncertainty in the input values was considered (Fig. 7).

Sensitivity analysis was applied to each criterion (indicator) for identifying the impact of changes, introduced to input data values and weights, on evaluation outcomes. Results due to input variations revealed no change in rankings. Applying the sensitivity analysis to weights, the vulnerability hotspots were somewhat sensitive to the age and height criteria of buildings. If we assumed that age with respect to precast concrete buildings and/or height values would be of great importance in building vulnerability (but very far from the original weight values), this would cause possible rank reversals of vulnerability hotspots. Based on the results, we noticed that in our case study, the sensitivity analysis helped more to reveal the construction particularities of the tested areas. This observation can be explained in the light that the considered 
Table 6 Characteristics of the four census tracts selected for uncertainty analysis, in terms of number of buildings and loss estimation results for the maximum earthquake scenario, according to different height classes and construction periods (defined according to SeisDaRo classification)

\begin{tabular}{|c|c|c|c|c|c|c|c|c|}
\hline \multirow{2}{*}{$\begin{array}{l}\text { Census } \\
\text { tract ID }\end{array}$} & \multirow[t]{2}{*}{ Type of indicator } & \multicolumn{3}{|l|}{ Height } & \multicolumn{4}{|c|}{ Construction period } \\
\hline & & $\begin{array}{l}\text { Low }(<2 \\
\text { storeys })\end{array}$ & $\begin{array}{l}\text { Medium } \\
(2-5 \\
\text { storeys })\end{array}$ & $\begin{array}{l}\text { High }(>5 \\
\text { storeys) }\end{array}$ & $\begin{array}{l}\text { PreCode } \\
(<1963)\end{array}$ & $\begin{array}{l}\text { LowCode } \\
\text { (1963-1977) }\end{array}$ & $\begin{array}{l}\text { ModerateCode } \\
(1978-1991)\end{array}$ & $\begin{array}{l}\text { HighCode } \\
(<1991)\end{array}$ \\
\hline 401 & \multirow[t]{4}{*}{ Total number of buildings } & 1367 & 286 & 26 & 1493 & 32 & 22 & 132 \\
\hline 507 & & 6104 & 81 & 25 & 2337 & 1944 & 859 & 1070 \\
\hline 202 & & 5655 & 111 & 50 & 2552 & 1526 & 623 & 1115 \\
\hline 207 & & 1960 & 86 & 59 & 1187 & 399 & 146 & 373 \\
\hline 401 & \multirow{4}{*}{$\begin{array}{l}\% \text { of buildings affected by the } \\
\text { maximum possible earthquake }\end{array}$} & 11.9 & 12.2 & 15.4 & 12.3 & 15.6 & 13.6 & 6.8 \\
\hline 507 & & 17.1 & 4.9 & 4.0 & 13.3 & 20.5 & 25.5 & 10.9 \\
\hline 202 & & 18.7 & 8.1 & 2.0 & 15.4 & 23.8 & 28.3 & 12.3 \\
\hline 207 & & 18.0 & 9.3 & 13.6 & 15.7 & 25.6 & 26.0 & 11.3 \\
\hline
\end{tabular}

Fig. 7 Graph of the ranking fluctuations when uncertainty in the criteria scores is considered $( \pm 30 \%$ in scores uncertainty; Monte-Carlo analysis with 10,000 simulations). The map in the right corner locates the four most vulnerable census tracts selected for the uncertainty and sensitivity analyses of the built environment

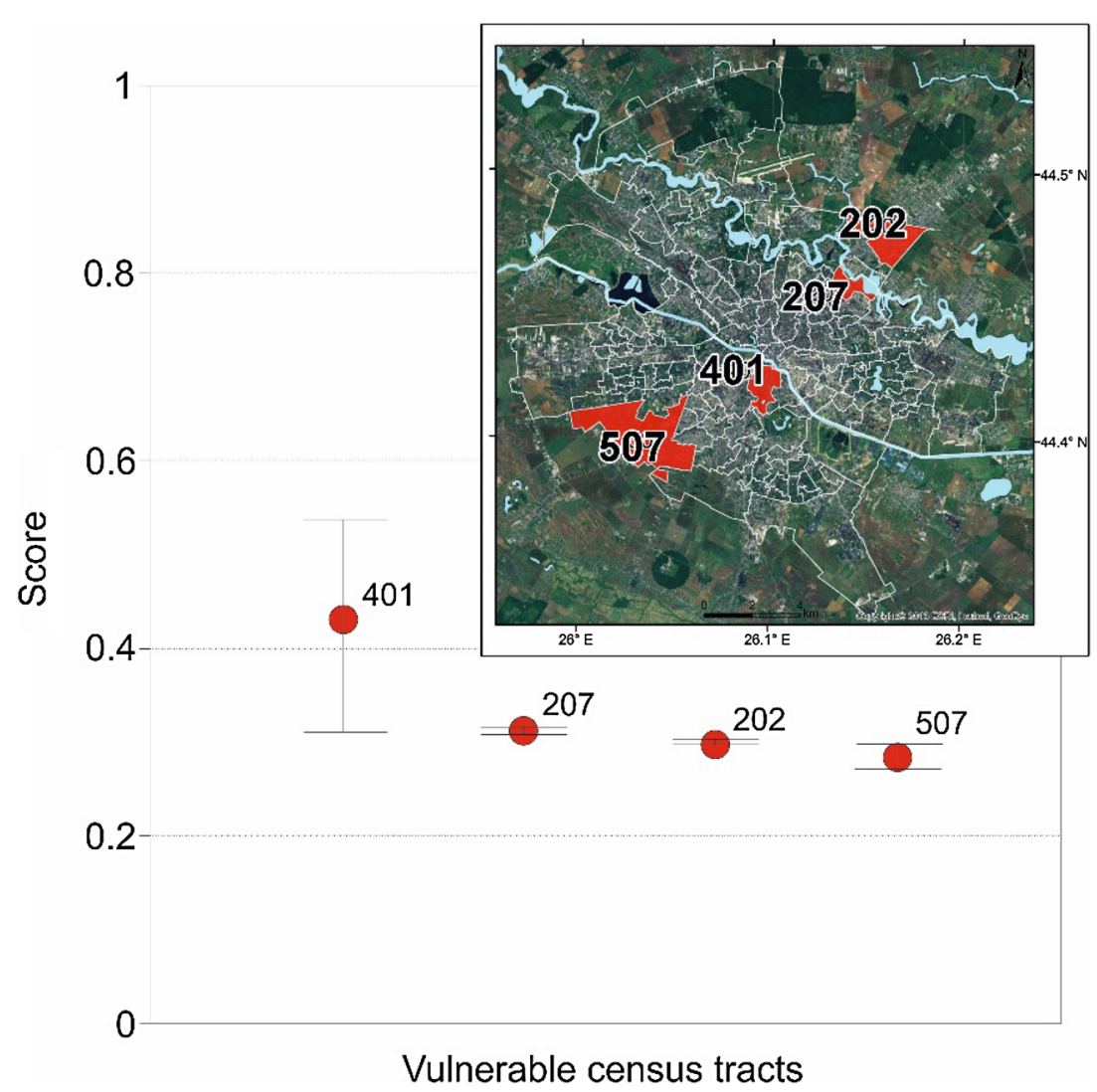

criteria have almost the same importance in building vulnerability in Bucharest.

\section{Conclusions}

Our approach introduces an innovative, multidisciplinary methodology for modeling seismic vulnerability based on both physical and social criteria for an important case study area prone to earthquakes: Bucharest. The methodological approach advanced a mix of spatial, post-processed (through multicriteria analysis) socioeconomic data, and analytical methods (IDCM and vulnerability functions) with which to estimate urban vulnerabilities using GIS.

By applying a mixture of techniques typical for earthquake engineering analyses with other procedures derived from the social sciences, a more complex image has emerged in the shape of the total earthquake vulnerability 
index of Bucharest and its 128 census tracts in 2011. The integration of multiple earthquake scenarios and building loss estimates at a neighborhood scale enabled better consideration of the direct seismic effects.

The results pointed out two main causes for the high vulnerability of Bucharest: (1) an ageing, poorly maintained stock of buildings, which is not replaced by new construction that adhere to antiseismic building standards; and (2) the distribution pattern of social vulnerability with high values found towards the peripheral areas of the city, where the number of persons with a lower prospect of quickly recovering (in an economic context) after an earthquake is greater. Although high social vulnerability areas overlap in many cases with high building-vulnerability areas, there are some cases (like in the center of Bucharest) where the mixture is greater.

The applicability and good fit of the results, when compared to previous studies, past events, or expert predictions, underlines that the proposed methodology provides a robust solution to the assessment of vulnerability in Bucharest. The method is also an input for subsequent urban risk mitigation activities. Although the disadvantages and uncertainties typical in modeling were accentuated by the available data, the final vulnerability result indicates validity, and is in accordance with expert-level understanding about how the city is developing. We believe that the resulted vulnerability map could therefore be integrated into the urban development policies of future strategies. The need for such policies is urgent-as the high number of census tracts (more than 20) located within the high vulnerability class would seem to indicate. Applying this methodology helped various refinements of previous studies, and provided the advantage of inquiry into social vulnerability at census tract scale. The flexibility of the framework allows ease of implementation for other case studies using different datasets.

Acknowledgements This work was supported by The Executive Unit for Financing the Higher Education and University Researches (UEFISCDI); through the REVEAL Project No. 285/2011 and through the NUCLEU CREATOR Programme, Project No. PN-1635-02-03. We highly acknowledge the contribution of the reviewers.

Open Access This article is distributed under the terms of the Creative Commons Attribution 4.0 International License (http://crea tivecommons.org/licenses/by/4.0/), which permits unrestricted use, distribution, and reproduction in any medium, provided you give appropriate credit to the original author(s) and the source, provide a link to the Creative Commons license, and indicate if changes were made.

\section{References}

Armaş, I. 2006. Earthquake risk perception in Bucharest, Romania. Risk Analysis 26(5): 1223-1234.
Armaş, I. 2008. Social vulnerability and seismic risk perception. Case study: The historic center of the Bucharest Municipality/ Romania. Natural Hazards 47(3): 397-410.

Armaş, I. 2012. Multi-criteria vulnerability analysis to earthquake hazard of Bucharest, Romania. Natural Hazards 63(2): $1129-1158$.

Armaş, I., and E. Avram. 2008. Patterns and trends in the perception of the seismic risk. Case study: Bucharest Municipality/Romania. Natural Hazards 44(1): 147-161.

Armaş, I., and A. Gavriş. 2013. Social vulnerability assessment using spatial multi-criteria analysis (SEVI model) and the Social Vulnerability Index (SoVI model)—A case study for Bucharest, Romania. Natural Hazards and Earth System Sciences 13: 1481-1499.

Armaş, I., and M. Radulian. 2014. Spatial multi-criteria risk assessment for earthquake hazards in Bucharest, Romania. In Earthquake hazard impact and urban planning, ed. Dan M. Boştenaru, I. Armaş, and A. Goretti, 127-149. Dordrecht: Springer.

Armaş, I., and A. Gavriş. 2016. Census-based social vulnerability assessment for Bucharest. Procedia Environmental Sciences 32: $138-146$.

Balan, S.F., D. Toma-Danila, and B.F. Apostol. 2016. Reinforced concrete buildings behaviour in the Metropolis of Bucharest during strong earthquakes in Romania. In Proceedings of the International Conference on Urban Risks ICUR2016, 149-155. 30 June-2 July 2016, Lisbon, Portugal.

Birkmann, J. 2006. Measuring vulnerability to promote disaster resilient societies: Conceptual frameworks and definitions. Tokyo: United Nations University Press.

Blaikie, P., T. Cannon, I. Davis, and B. Wisner. 1994. At risk: Natural hazards, people's vulnerability, and disasters. London: Routledge.

Bucharest General Municipality. 2016. List of buildings technically evaluated and classified into seismic risk classes. http://www. pmb.ro/servicii/alte_informatii/lista_imobilelor_exp/docs/Lista_ imobilelor_expertizate.pdf. Accessed 29 Dec 2016.

Chen, Y., J. Yu, and S. Khan. 2010. Spatial sensitivity analysis of multi-criteria weights in GIS-based land suitability evaluation. Environmental Modelling and Software 25(12): 1582-1591.

Chen, M., M.D. Wood, C. Linstead, and E. Maltby. 2011. Uncertainty analysis in a GIS-based multicriteria analysis tool for river catchment management. Environmental Modelling and Software 26(4): 395-405.

Crosetto, M., S. Tarantola, and A. Saltelli. 2000. Sensitivity and uncertainty analysis in spatial modelling based on GIS. Agriculture, Ecosystems and Environment 81: 71-79.

Crosetto, M., and S. Tarantola. 2001. Uncertainty and sensitivity analysis: Tools for GIS based model implementation. International Journal of Geographical Information Science 15(5): $415-437$.

Coppola, D. 2007. Introduction to disaster management. Burlington, MA: Elsevier.

Duzgun, H.S.B., M.S. Yucemen, H.S. Kalaycioglu, K. Celik, S. Kemec, K. Ertugay, and A. Deniz. 2011. An integrated earthquake vulnerability assessment framework for urban areas. Natural Hazards 59(2): 917-947. doi:10.1007/s11069-011-98086.

Erdik, M., K. Şeşetyan, M.B. Demircioğlu, U. Hancılar, and C. Zülfikar. 2011. Rapid earthquake loss assessment after damaging earthquakes. Soil Dynamics and Earthquake Engineering 31(2): 247-266.

Eurostat. 2014. Housing condition report. http://ec.europa.eu/eurostat/ statistics-explained/index.php/Housing_conditions. Accessed 12 Jan 2017. 
Feizizadeh, B., T. Blaschke, and H. Nazmfar. 2014. GIS-based ordered weighted averaging and Dempster Shafer methods for landslide susceptibility mapping in Urmia lake basin, Iran. International Journal of Digital Earth 7(8): 688-708.

Fekete, A. 2009. Validation of a social vulnerability index in context to river-floods in Germany. Natural Hazards and Earth System Sciences 9(2): 393-403.

FEMA (Federal Emergency Management Agency). 2014. HAZUSMH: Multi-hazard loss estimation methodology. http://www. fema.gov/hazus. Accessed 11 Jun 2017.

Giardini, D., J. Woessner, L. Danciu, F. Cotton, H. Crowley, G. Grünthal, R. Pinho, G. Valensise, and the SHARE consortium. 2013. Seismic hazard harmonization in Europe (SHARE): Online data resource. doi:10.12686/SED-00000001-SHARE.

Gu, D., P. Gerland, F. Pelletier, and B. Cohen. 2015. Risks of exposure and vulnerability to natural disasters at the city level: A global overview. United Nations Technical Paper No. 2015/2. New York: United Nations.

Hinkel, J. 2011. Indicators of vulnerability and adaptive capacity: Towards a clarification of the science-policy interface. Global Environmental Change 21(1): 198-208.

INS (National Institute of Statistics), Romania. 2017. Results of the 2011 population and housing national census. http://www. recensamantromania.ro/rezultate-2. Accessed 11 Jun 2017.

Ionescu, C., R. Klein, J. Hinkel, K. Kavi Kumar, and R. Klein. 2009. Towards a formal framework of vulnerability to climate change. Environmental Modelling and Assessment 14(1): 1-16.

ITC (International Institute for Aerospace Survey and Earth Sciences). 2001. ILWIS 3.0 user's guide. http://52north.org/ communities/ilwis/ilwis-open/user-guide. Accessed 20 Jan 2017.

Janssen, R., and M. van Herwijnen. 1994. DEFINITE A system to support on a finite set of alternatives (Software package and user manual). Dodrecht: Kulwer Academic Publishers.

Karimzadeh, S., B. Feizizadeh, and M. Matsuoka. 2017. From a GISbased hybrid site condition map to an earthquake damage assessment in Iran: Methods and trends. International Journal of Disaster Risk Reduction 22: 23-36.

Kasperson, J., and R. Kasperson. 2005. The social contours of risk: Risk analysis, corporations and the globalization of risk. London: Earthscan.

Lang, D., S. Molina-Palacios, C. Lindholm, and S.F. Balan. 2012. Deterministic earthquake damage and loss assessment for the city of Bucharest, Romania. Journal of Seismology 16(1): 67-88.

Marquis, F., J.J. Kim, J.K. Elwood, and S.E. Chang. 2015. Understanding post-earthquake decisions on multi-storey concrete buildings in Christchurch, New Zealand. Bulletin of Earthquake Engineering 15(2). doi:10.1007/s10518-015-9772-8.

Marmureanu, G., C.O. Cioflan, and A. Marmureanu. 2010. Researches on local seismic hazard (microzonation) for metropolitan Bucharest area. Iasi: Tehnopress (in Romanian).

Molina, S., D.H. Lang, C.D. Lindholm, and F. Lingvall. 2010. User manual for the earthquake loss estimation tool: SELENA. http:// selena.sourceforge.net. Accessed 11 Jun 2017.

Necula, G.C., S. McPeak, and W. Weimer. 2002. CCured: Type-safe retrofitting of legacy code. ACM SIGPLAN Notices 37(1): $128-139$

NIEP (National Institute for Earth Physics), Romania. 2016. BIGSEES Project's earthquake catalog. http://bigsees.infp.ro/ Results.html. Accessed 29 Dec 2016.

Ouma, Y., E.C. Kipkorir, and R. Tateishi. 2011. MCDA-GIS integrated approach for optimized landfill site selection for growing urban regions: An application of neighborhood-proximity analysis. Annals of GIS, 17(1): 43-62.

Pavel, F., and R. Vacareanu. 2016. Scenario-based earthquake risk assessment for Bucharest, Romania. International Journal of Disaster Risk Reduction 20: 138-144.
Pavel, F., R. Vacareanu, J. Douglas, M. Radulian, C.O. Cioflan, and A.H. Barbat. 2016. An updated probabilistic seismic hazard assessment for Romania and comparison with the approach and outcomes of the SHARE Project. Pure and Applied Geophysics 173(6): 1881-1905.

Ravalico, J.K., G.C. Dandy, and H.R. Maier. 2010. Management Option Rank Equivalence (MORE) a new method of sensitivity analysis for decision-making. Environmental Modelling and Software 25(2): 171-181.

Rufat, S. 2009 From mural map to GIS: Mapping urban vulnerability in Bucharest. In Urban and regional data management: UDMS, ed. A. Krek, M. Rumor, S. Zlatanova, and E. Fendel, 301-313. London: Taylor and Francis Group.

Saaty, T.L. 1980. The analytic hierarchy process. New York: McGraw Hill.

Saltelli, A., S. Tarantola, and F. Campolongo. 2000. Sensitivity analysis as an ingredient of modelling. Statistical Science 15(4): 377-395.

Sterlacchini, S., S.O. Akbas, J. Blahut, O.C. Mavrouli, C. Garcia, B.Q. Luna, and J. Corominas. 2014. Methods for the characterization of the vulnerability of elements at risk. In Mountain risks: From prediction to management and governance, ed. T. Asch, J. Corominas, S. Greiving, J.P. Malet, and S. Sterlacchini, 233-273. Dordrecht: Springer.

Strasser, F.O., J.J. Bommer, K. Sesetyan, M. Erdik, Z. Cagnan, J. Irizarry, X. Goula, A. Lucantoni, F. Sabetta, I.E. Bal, H. Crowley, and C. Lindholm. 2008. A comparative study of European earthquake loss estimation tools for a scenario in Istanbul. Journal of Earthquake Engineering 12(2): 246-256.

Thywissen, K. 2006. Core terminology of disaster reduction: A comparative glossary. In Measuring vulnerability to natural hazards: Towards disaster resilient societies, ed. J. Birkmann, 448-496. New York: United Nations University Press.

Toma-Danila, D., and I. Armas. 2017. Insights on the possible seismic damage of residential buildings in Bucharest, Romania, at neighborhood resolution. Bulletin of Earthquake Engineering 15(3): 1161-1184.

Toma-Danila, D., C. Zulfikar, E.F. Manea, and C.O. Cioflan. 2015a. Improved seismic risk estimation for Bucharest, based on multiple hazard scenarios and analytical methods. Soil Dynamics and Earthquake Engineering 73: 1-16.

Toma-Danila, D., C.O. Cioflan, S.F. Balan, and E.F. Manea. 2015b. Characteristics and results of the near real-time system for estimating the seismic damage in Romania. Mathematical Modelling in Civil Engineering 11(1): 33-41.

Trendafiloski, G., M. Wyss, P. Rosset, and G. Marmureanu. 2009. Constructing city models to estimate losses due to earthquakes worldwide: Application to Bucharest, Romania. Earthquake Spectra 25(3): 665-685.

Turner, B., R. Kasperson, P. Matson, J. McCarthy, R. Corell, L. Christensen, N. Eckley, J. Kasperson, A. Luers, M.L. Martello, C. Polsky, A. Pulsipher, and A. Schiller. 2003. A framework for vulnerability analysis in sustainability science. Proceedings of the National Academy of Sciences 100(14): 8074-8079.

USGS (United States Geological Survey). 2016. Earthquake statistics-Worldwide earthquakes 2000-2015. https://earthquake. usgs.gov/earthquakes/browse/stats.php. Accessed 10 Jun 2017.

van der Veen, A., E. Dopheide, D. Parker, S. Tapsell, J. Handmer, C. Gregg, C. Bonadonna, and F. Ferrara. 2009. State-of-art on vulnerability of socio-economic systems. Del. 1.1.3 of the ENSURE EC FP7. Project: Methodologies to assess vulnerability of structural, territorial and economic systems. Brussels: European Commission.

Walker, B.B., C. Taylor-Noonan, A. Tabbernor, T. McKinnon, H. Dal, D. Bradley, N. Schuurman, and J.J. Clague. 2014. A multicriteria evaluation model of earthquake vulnerability in Victoria, British Columbia. Natural Hazards 74(2):1209-1222. 